\title{
Changes in oral health related knowledge, attitudes and behaviours following school based oral health education and atraumatic restorative treatment in rural Tanzania
}

\author{
Anne Nordrehaug Åstrøm ${ }^{1}$ and Kijakazi Obed Mashoto ${ }^{2,3}$ \\ 1) Department of Clinical Dentistry, University of Bergen \\ 2) Centre for International Health, University of Bergen \\ 3) National Institute for Medical Research, Tanzania \\ Correspondence: Anne Nordrehaug Åstrøm, Department of Clinical Dentistry, Årstadveien 17, NO-5009 Bergen, Norway \\ E-mail: anne.nordrehaug@cih.uib.no Telephone: +4755 586483
}

\begin{abstract}
Objectives: The following questions were addressed; to what extent is sugar consumption, tooth brushing, and oral health related attitudes and knowledge subject to change following a combined atraumatic restorative treatment (ART) /oral health education (OHE) program? Are changes in intended sugar avoidance associated with changes in cognitions as specified by the Theory of Planned Behaviour (TPB)? Are changes in oral health related knowledge associated with changes in attitudes and oral health behaviour?

Method: A total of 1306 (follow-up prevalence 73.8\%) primary school students in Kilwa, Tanzania completed interviews before and after a combined ART/OHE program. Post intervention at 6 months follow-up assessed changes in oral health related knowledge, attitudes, and behaviours. Complete baseline and follow-up interviews were obtained from 221 and 1085 students who received ART/OHE and OHE only at schools, respectively.

Results: Improvement was obtained with attitudes towards sugar avoidance, knowledge, and tooth brushing (effect sizes in the range 0.1-0.3). Within individual changes did not differ significantly between students receiving ART/ OHE and OHE only. Change scores of intended sugar avoidance associated in the expected direction with changes in sugar consumption. Attitudes and norms with respect to sugar avoidance deteriorated and improved among subjects who respectively decreased and increased intended sugar avoidance. Tooth brushing increased in students who improved oral knowledge.

Conclusion: School based ART/OHE improved pupils' tooth brushing, knowledge, and attitudes, but had no effect on sugar consumption. This study provided support for the validity of the TPB in predicting changes in intended sugar avoidance and reported sugar intake.
\end{abstract}

\section{BACKGROUND}

In Tanzania, dental diseases have remained at moderate levels, as approximately $30-40 \%$ of the population irrespective of age, is reportedly free from dental caries (1). However, children and adolescents with untreated dentinal lesions and pain have been cited as the main reason for seeking dental care (1-3). Poor oral hygiene is very common with a substantial proportion of youth having calculus and gingivitis (4-6). Traditionally, the exposure to dental health care services has been low with a dentist to population ratio of $1: 347,273(7,8)$. To compensate for the limited number of dental professionals and to make dental care available for the youth population, ART and oral health education, OHE, have been recommended. According to the World Health Organization (WHO), the ART is recognized to be appropriate for public oral health care services in developing countries $(9,10)$. So far, this approach has been introduced in three regions of Tanzania (10).

Use of oral hygiene measures, fluorides, dental services, and restricted sugar- and tobacco consumption contributes to the control of oral diseases, making prevention a priority means to cope with the oral health situation in non-occidental settings (11). Bad oral hygiene conditions and the anticipated increase in caries prevalence following economic progress and changed dietary habits should be challenged primarily through preventive efforts (11). Although OHE has been incorporated for years into the Tanzanian School Health Program, evidence suggests that pupils present with inappropriate knowledge and deficient tooth brushing skills (12-14). Sugar consumption has remained at a moderate level, although commercialized sugar products gradually gain social importance (15). Traditionally, the Tanzanian oral health education program has been evaluated in terms of the existing levels and distribution of oral diseases, whereas information about the scope and extent of oral health related behaviours have been almost neglected $(6,13)$. Despite considerable work done for OHE in Tanzanian schools, few studies have been theory based and evaluated OHE in terms of oral health related knowledge, attitudes and behaviours.

\section{Theoretical framework}

Theory based interventions are based on the idea that it is possible to change cognitions and that those changes in turn will promote changes in prospective behaviours (16). One popular theoretical framework for the pre- 
diction and change of health behaviours is the Theory of Planned Behaviour (TPB) $(17,18)$. The TPB includes perceived behavioural control together with attitude and subjective norm, as determinants of behavioural intention, considering intentions to be an additive function of attitude, subjective norm and perceived control. These constructs, in turn, influence subsequent behaviour through behavioural intentions (18). According to the TPB, changes in behaviour in response to information encountered across time follow from changes in intentions, whereas changes in intentions follow from changes in attitudes, subjective norms and perceived control. The predictive utility of the TPB has been supported for a wide range of health- and oral health behaviours $(19,20)$. Studies have shown that the TPB provides a useful description of modifiable cognitions related to sugar consumption of adolescents and young adults in East Africa $(15,21)$. In those studies, attitudes, subjective norms and perceived control correlated with the intended and self-reported sugar consumption $(15,21)$. Importantly, cognitive correlates specify targets for the promotion of dietary habits in non-occidental cultural contexts. Within the framework of the TPB, persuasive communication might be tailored to modify cognitions associated with particular behaviours. It is unclear, however, what magnitude of behaviour change could be expected following interventions that successfully change cognitive behavioural determinants (22). No previous study has investigated to what extent change in TPB specified cognitions is related to change in oral health related behaviours following OHE targeting young people in developing countries.

\section{Purpose}

Using a 6 months prospective ART/OHE approach, this study assessed the validity of the TPB components in predicting changes in intended and self-reported oral health related behaviours focusing school going adolescents from a deprived district of Tanzania. The following questions were addressed: To what extent is the TPB constructs, sugar consumption, tooth brushing and oral health related knowledge subject to change following a combined ART/OHE program? Are observed changes in intention to avoid sugared snacks associated with changes in attitudes, subjective norms and perceived control and with reported sugar consumption as specified by the TPB? This study also explored whether changes in oral health related knowledge associated with changes in attitudes towards sugar avoidance, tooth brushing frequency, and reported sugar consumption. It was hypothesized that increased intention to avoid sugar products would associate with changes towards more positive attitudes, subjective norms and perceived control, and with reduced sugar consumption. Moreover, it was hypothesized that improved oral health related knowledge would associate with more positive attitudes towards sugar avoidance, increased tooth brushing frequency, and decreased intake of sugared snacks.

\section{METHODS}

The present study was implemented in Lindi region in south-eastern Tanzania in 2008. Lindi is one of the most sparsely populated regions of the Tanzanian main land (23). This region is divided into six districts; of which Kilwa was purposively selected, since the fluoride concentration in the drinking water is low $(0.2$ $\mathrm{mg} / \mathrm{L}$ ) and the district is particularly deprived regarding oral health care services. This study utilized a multi-group before-after design to estimate changes in knowledge, attitudes and behaviours related to oral health following ART and OHE. Data was generated from interviews with pupils at baseline (pre-intervention) and 6 months after the last scheduled intervention appointment (post-intervention) and from a full mouth clinical oral examination conducted at baseline. The study population comprised of pupils attending their $6^{\text {th }}$ primary public school year $(\mathrm{N}=8,609)$. A stratified one stage cluster sample design was utilized for the baseline survey. A detailed description of the calculation of sample size and the sampling procedure is provided elsewhere (24). One thousand seven hundred and eighty out of 2,465 eligible students, yielding a response rate of $72.2 \%$, consented to participate in the study. Their mean age was 13.8 years. Absence from school at the time of data collection was the main reason for non-participation. Ethical clearance was granted by the National Institute for Medical Research in Tanzania, the Regional Committee for Medical Research Ethics in Norway, and the Norwegian Data Inspectorate. Permission for students' participation was sought from school authorities. Ministry of Education and Vocational Training through the District Council approved the conduct of the study. Written and verbal informed consent to participate in the study was also obtained from schoolchildren and their parents.

\section{Interview}

Identical interview schedules were administered at baseline and follow-up by trained research assistants and completed by the students in face to face interviews. Each interview was conducted in a private and quiet place outside the classroom. The interview schedule was originally constructed in English, then translated into Kiswahili, and subsequently back-translated into English. It was pilot tested prior to its use in the field. Parents' level of education was originally scored (1) no formal education, (2) attended, but not completed primary school, (3) completed primary school, (4) attended, but not completed secondary school, (5) completed secondary school, (6) college or university education. For the purpose of analysis the educational variables (mother's and father's education) were recoded into $(0)$ low education (including original categories 1 and 2) and (1) high education (including original categories 3, 4, 5 and 6). The cut-off point was justified by the distribution of the variables. Sugar consumption was constructed as a sum score of 5 questions in terms of "How frequently do you take biscuits, chocolates, ice 
sticks, soda, sugared fruit juice and sugared coffee/ tea"? using a 5 point scale from (1) never to (5) more than once a day. The higher the score the more frequent intake of sugared foods and drinks. Tooth brushing frequency was measured on a 5-point scale ranging from (1) never to (5) more than once a day. Knowledge related to oral health was assessed as a sum score of 9 statements in terms of; "are the following (bacteria, lack of hygiene, sugary food frequently, lots of sugary foods) causes of caries" and "can the following prevent dental caries from occurring" (reduced intake of sugary foods, regular brushing, use of fluoride toothpaste, regularly daily tooth brushing, stop eating sugared foods) assessed on a scale (1) yes, (2) no, (3) I do not know. The higher the sum score the weaker the knowledge related to oral health. Intention to avoid sugared snacks and drinks was assessed using two items "I intend to avoid frequent intake of sugared snacks and drinks" and "It is likely that I will avoid frequent intake of sugared snacks and drinks" each measured on a scale in the range (1) strongly agree (5) strongly disagree. The higher the sum score the weaker the intention (Cronbach's alpha 0.71). Attitudes towards avoiding sugared snacks and drinks were assessed using 4 items, e.g. "For me to avoid frequent intake of sugared snacks and drinks is useful" using a scale ranging from (1) strongly agree to (5) strongly disagree. The higher the sum score the weaker the attitudes towards sugar avoidance (Cronbach's alpha 0.70). Subjective norms related to avoiding sugared snacks and drinks in the future was measured in terms of "People who are important to me want me to avoid sugared snacks and drinks using a scale (1) strongly agree to (5) strongly disagree. Perceived control related to avoiding sugared snacks and drinks in the future was assessed by a sum score of three items; e.g. "If I want to I can easily avoid sugared snacks and drinks", using a scale (1) strongly agree to (5) strongly disagree. The higher the sum score the weaker the perceived control regarding sugar avoidance (Cronbach's alpha 0.60). The TPB constructs and questions regarding oral health related behaviours utilized in this study have previously shown to be valid and reliable when used on several occasions among young people in East Africa $(15,21)$.

\section{ART and $O H E$ intervention}

Following a full mouth oral clinical examination completed by one trained and calibrated dentist (KM), teeth with caries, but with no history of pain or tenderness were treated according to the ART manual $(25,26)$. Teeth with a grossly damaged crown and with pain and tenderness to percussion, teeth with obvious pulp involvement, and teeth judged to be un-restorable were extracted under local anaesthesia. For a detailed description of the clinical examination and the ART treatment procedure which was provided free of charge, see (24).

After completion of interviews and clinical exami- nations in that order, the participants in each school were gathered in a classroom to receive OHE. The OHE component of the intervention was implemented with the aim to increase students' knowledge of oral health problems, improve their attitudes towards sugar restriction, decrease the frequency of daily intake of sugared snacks and increase daily tooth brushing frequency. A team of one dentist, one assistant dental officer, one dental therapist, and one teacher conducted the educational sessions, giving room for participants to ask questions for clarification. The sessions lasted approximately thirty to forty-five minutes. One teacher from each participating school was trained by dental staff to continue to provide OHE covering topics on causes, symptoms, and prevention of dental caries. Teacher provided OHE was continued on a weekly basis for a period of 6 months and delivered as an interactive talk between teachers and pupils around key oral health messages. The key oral hygiene messages included were brush with fluoride toothpaste and use a pea size amount of it, brush for three minutes at least twice a day, and replace toothbrush when bristles start to get out of shape. Each participant was given a toothbrush to be used at home. Information on the consequences of frequent sugar consumption on caries development and progression was also provided.

\section{Statistical analysis}

Data were analysed using PASW statistics 18.0. Design effect due to clustering and stratification was adjusted using Complex Samples. Internal consistency reliability was evaluated by Cronbach's alpha. Change scores of the TPB components, sugar consumption, tooth brushing and knowledge were constructed by subtracting post- from pre-treatment scores. A positive change score indicated improvement whereas a negative score indicated deterioration with respect to the TPB constructs and oral health related knowledge. A negative change score indicated improvement and a positive change score indicated deterioration with respect to sugar consumption and tooth brushing frequency, respectively. To quantify changes, effect size statistics were calculated by dividing the mean change scores by the SD of the corresponding pre-treatment score. Cohen (27) described effect size statistics of $<0.2$ to indicate a small, clinically meaningful magnitude of change, effect size statistics in the range 0.20.7 to indicate moderate change, and effect size statistics of $>0.7$ to indicate large change. Paired sample ttests and General Linear Models (GLM) for repeated measures was used to assess the within individual change of the TPB constructs, knowledge related to oral health, sugar consumption, and tooth brushing frequency in the total sample and according to groups receiving ART/OHE and OHE only. GLM for repeated measures was also used to test whether changes in attitudes, subjective norms, perceived behavioural control, sugar consumption, tooth brushing, and knowledge from baseline to follow up correlated with 


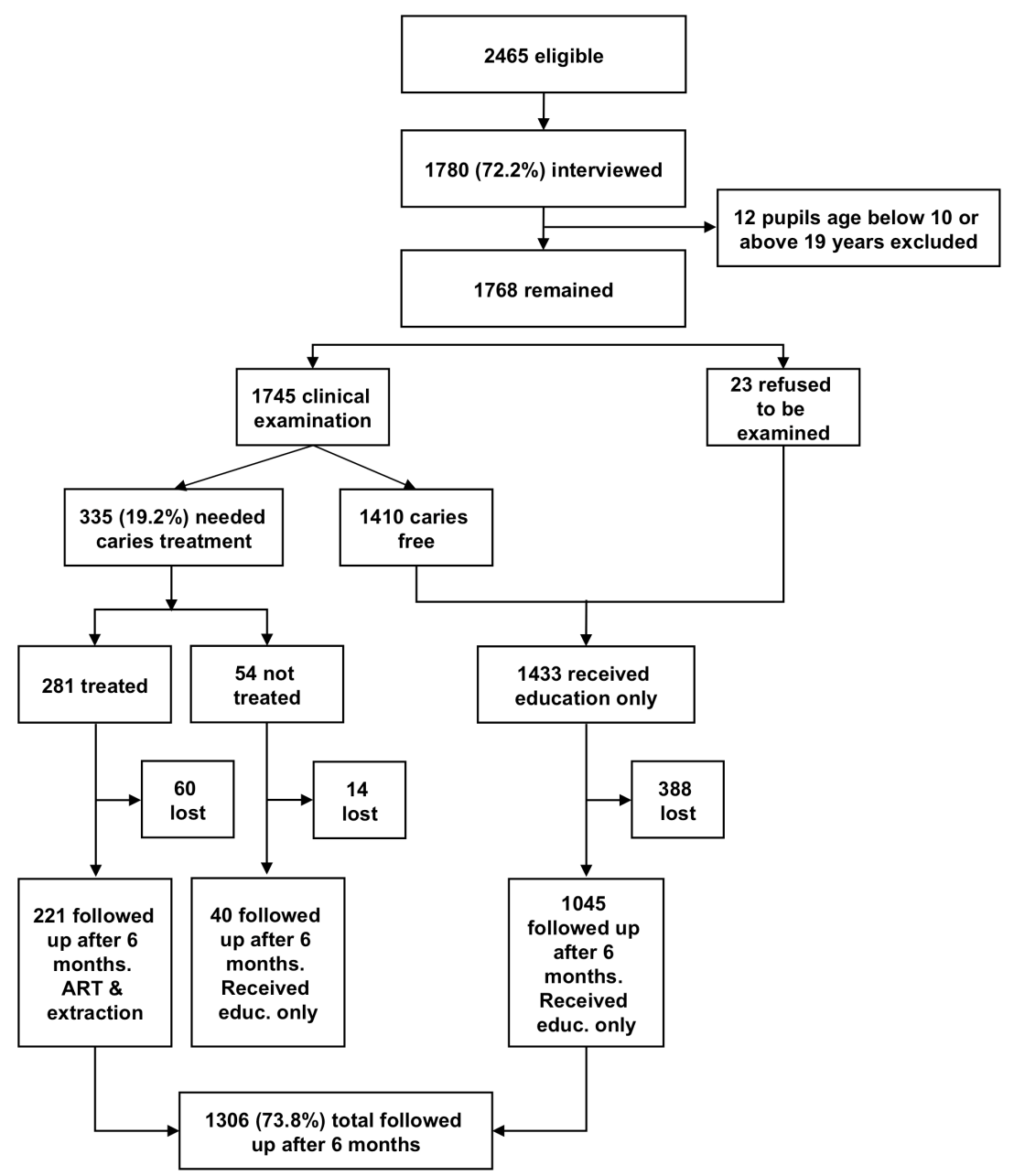

Figure 1. The 6 month treatment and oral health education intervention among Tanzanian primary school students, a flow chart of attendance (24).

change scores of intention and oral health related knowledge. Bonferroni post hoc test was used to control for multiple comparisons.

\section{RESULTS}

As shown in Fig. 1, the interviews were completed by $1,768(72.2 \%)$ students at baseline, of who 1306 (follow up rate $73.8 \%$ ) completed an identical interview at 6 months follow-up. A total of 335 (19.2\% of 1,745 clinically examined at baseline) students were identified with treatment need (i.e., DMFT $>0$ ), $8.4 \%$ of the students was in need of filling therapy, and $10.6 \%$ was in need of both fillings and tooth extraction. Two hundred and eighty one students received treatment. At 6 months follow-up, 221 subjects who received treatment responded to the follow-up interview. Totals of 1,433 students without treatment need and 54 students who did not show up for treatment received OHE, only. Of those, 1,045 and 40 students were reinterviewed at follow-up.

As shown in Table 1, differences occurred between students who did $(n=1,306)$ and did not $(n=462)$ respond to the follow-up interview with respect to base- line socio-demographic factors, i.e. age, sex and place of residence, and with respect to attitudes towards sugar avoidance and tooth brushing frequency. As shown in Table 2, the intervention groups (ART/OHE versus OHE only) were comparable at both times of measurements with respect to the socio-demographic factors measured at baseline.

As depicted in Table 3, the mean attitude score was statistically significantly reduced from 11.0 to 10.7 between baseline and follow-up. Statistically significant changes were also observed with respect to perceived control, knowledge and tooth brushing. In the study group as a whole, perceived control with respect to sugar avoidance decreased, whereas knowledge and tooth brushing increased during the intervention period. The effect sizes were small to medium and ranged from 0.1 to 0.3 .

GLM repeated measures revealed no statistically significant two-way interactions with respect to the intervention groups and the TPB constructs, sugar consumption, tooth brushing and oral health knowledge (Table 4). Attitudes towards sugar avoidance improved moderately but statistically significantly between baseline and follow up in students receiving OHE only 
Table 1. Socio-demographics and TPB measures at baseline according to follow-up status.

\begin{tabular}{|c|c|c|c|}
\hline & $\begin{array}{l}\text { Lost to follow-up } \\
\qquad(\mathrm{N}=462)\end{array}$ & $\begin{array}{l}\text { Followed up } \\
(\mathrm{N}=1306)\end{array}$ & $\begin{array}{l}\text { Baseline } \\
(\mathrm{N}=1768)\end{array}$ \\
\hline \multicolumn{4}{|l|}{ Age: \% (n) } \\
\hline $10-14$ years & $58.8(272)^{* *}$ & $71.5(934)$ & $68.2(1206)$ \\
\hline $15-19$ years & $41.2(190)$ & $28.5(372)$ & $31.8(562)$ \\
\hline \multicolumn{4}{|l|}{ Sex: \% $(n)$} \\
\hline Boys & $55.8(258)^{* *}$ & $47.5(621)$ & $49.7(879)$ \\
\hline Girls & $44.2(204)$ & $52.5(685)$ & $50.3(889)$ \\
\hline \multicolumn{4}{|l|}{ Place of residence: $\%(n)$} \\
\hline Urban & $41.8(194)$ & $50.3(657)$ & $48.1(850)$ \\
\hline Rural & $58.2(268)^{* *}$ & $49.7(649)$ & $51.9(918)$ \\
\hline \multicolumn{4}{|l|}{ Mother's education: $\%(n)$} \\
\hline Low & $90.5(418)$ & $90.0(1175)$ & $90.1(1593)$ \\
\hline High & $9.5(44)$ & $10.0(131)$ & $9.9(175)$ \\
\hline \multicolumn{4}{|l|}{ Father's education: \% (n) } \\
\hline Low & $85.5(395)$ & $81.9(1070)$ & $82.9(1465)$ \\
\hline \multirow[t]{2}{*}{ High } & $14.5(67)$ & $18.1(236)$ & $17.1(303)$ \\
\hline & Mean (sd) & Mean (sd) & Mean (sd) \\
\hline $\begin{array}{l}\text { Intention to avoid sugared snacks } \\
\text { [theoretical range: high-low] }\end{array}$ & $4.6(2.2)$ & $4.4(2.1)$ & $4.5(2.1)$ \\
\hline $\begin{array}{l}\text { Attitudes to avoid sugared snacks } \\
\text { [theoretical range: high-low] }\end{array}$ & $11.2(2.3)$ & $10.9(2.5)^{*}$ & $11.0(2.5)$ \\
\hline $\begin{array}{l}\text { Subjective norms to avoid sugared snacks } \\
\text { [theoretical range: high-low] }\end{array}$ & $2.3(1.3)$ & $2.3(1.2)$ & $2.3(1.2)$ \\
\hline $\begin{array}{l}\text { Perceived control to avoid sugared snacks } \\
\text { [theoretical range: high-low] }\end{array}$ & $6.1(2.4)$ & $6.0(2.3)$ & $6.0(2.3)$ \\
\hline Sugared food and drinks (low-high) & $8.5(4.5)$ & $8.7(4.7)$ & $8.7(4.6)$ \\
\hline Tooth brushing (low-high) & $3.9(1.0)$ & $4.1(1.2)^{* *}$ & $4.0(1.1)$ \\
\hline Knowledge [theoretical range: high-low] & & & \\
\hline
\end{tabular}

Table 2. Socio-demographics and TPB constructs stratified by treatment groups at baseline and follow-up.

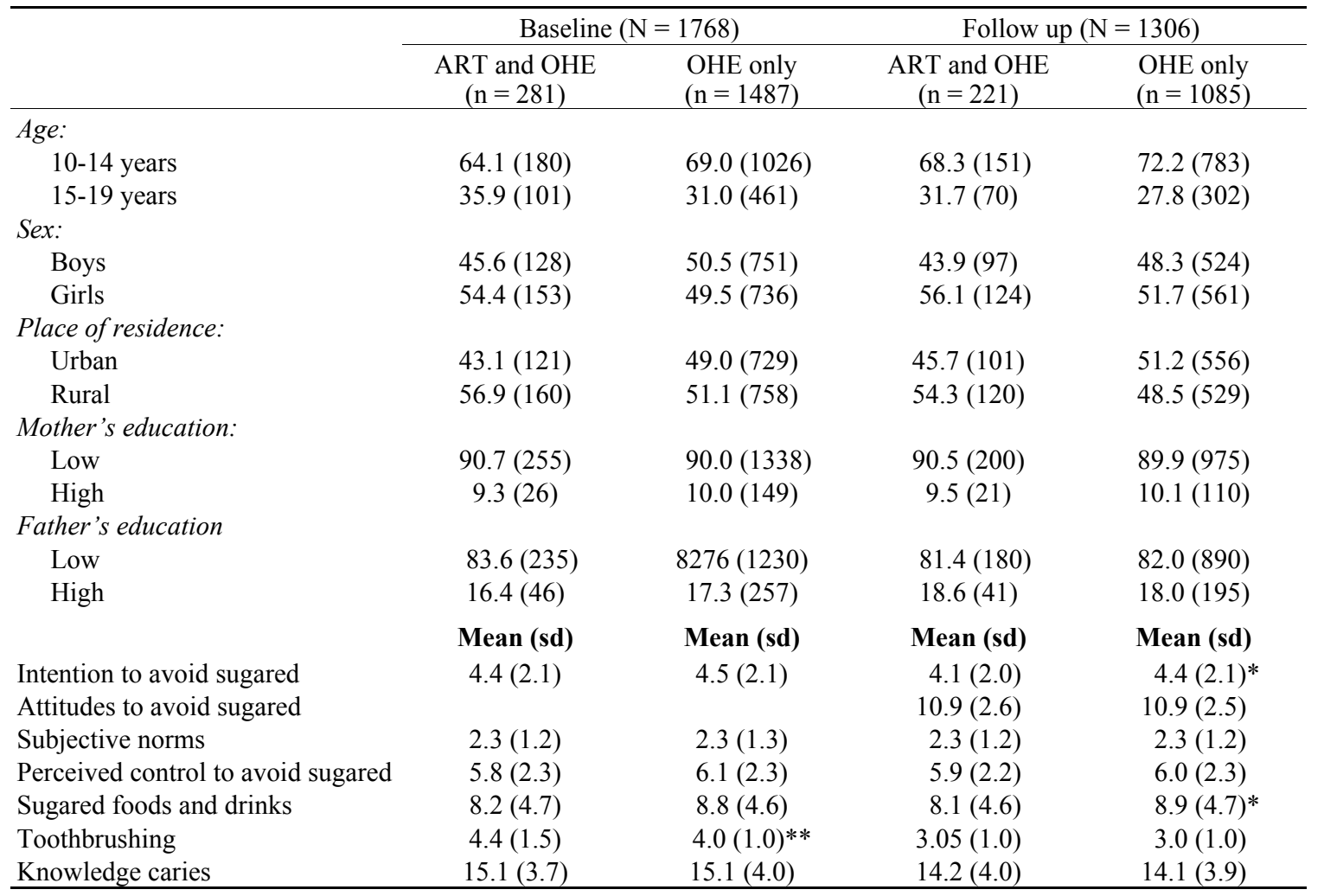


Table 3. The TPB constructs, oral health related knowledge and behaviours at baseline and follow up time points. Mean (sd) total scores, change scores, and effect sizes. Paired t-test ( $\mathrm{n}=1308)$.

\begin{tabular}{lccccc}
\hline & $\begin{array}{c}\text { Baseline } \\
\text { [theoretical range] }\end{array}$ & $\begin{array}{c}\text { Follow up } \\
\text { Mean (sd) [range] }\end{array}$ & $\begin{array}{c}\text { Paired t-test } \\
\text { P-value }\end{array}$ & $\begin{array}{c}\text { Change score } \\
\text { Mean (sd) }\end{array}$ & Effect size \\
\hline Intention[high-low] & $4.4(2.1)[2-10]$ & $4.5(2.0)[2-10]$ & 0.118 & -0.12 & 0.1 \\
Attitudes [high-low] & $11.0(2.5)[4-20]$ & $10.7(2.5)[4-20]$ & 0.020 & 0.2 & 0.1 \\
Subjective norms [high-low] & $2.3(1.2)[1-5]$ & $2.4(1.2)[1-5]$ & 0.159 & -0.1 & 0.1 \\
Perceived control [high-low] & $6.0(2.3)[3-15]$ & $6.3(2.4)[3-15]$ & 0.042 & -0.2 & 0.1 \\
Knowledge [high-low] & $15.6(3.9)[9-27]$ & $14.2(3.8)[9-28]$ & 0.001 & 1.0 & 0.3 \\
Tooth brushing [low-high] & $3.0(1.0)[0-4]$ & $3.2(0.7)[0-4]$ & 0.001 & -0.2 & 0.3 \\
Sugared foods[low-high] & $8.8(4.4)[0-24]$ & $8.9(4.6)[0-24]$ & 0.694 & 0.1 & 0.02 \\
\hline
\end{tabular}

Table 4. Mean scores and 95\% CI for TPB constructs and sugar behaviours at baseline and followup by intervention group. GLM repeated measures.

\begin{tabular}{|c|c|c|c|}
\hline & $\begin{array}{c}\text { ART and OHE }(\mathrm{n}=221)^{\mathrm{a}} \\
\mathrm{M}(95 \% \mathrm{CI})\end{array}$ & $\begin{array}{c}\text { OHE only }(\mathrm{n}=1087)^{\mathrm{a}} \\
\text { M }(95 \% \mathrm{CI})\end{array}$ & $\begin{array}{c}\text { Factor } \mathrm{x} \text { group }^{\mathrm{b}} \\
\mathrm{P} \text { value }\end{array}$ \\
\hline Attitude (baseline) & $10.9(10.6-11.3)$ & $10.9(10.7-11.0)$ & \\
\hline Attitude (follow-up) & $10.7(10.4-11.1)$ & $10.7(10.5-10.8)$ & \\
\hline Baseline/ follow-up & $\mathrm{P}=0.283$ & $\mathrm{P}=0.039$ & 0.985 \\
\hline Subjective norm (baseline) & $2.3(2.1-2.5)$ & $2.3(2.2-2.3)$ & \\
\hline Subjective norm (follow-up) & $2.4(2.3-2.6)$ & $2.3(2.2-2.4)$ & \\
\hline Baseline/ follow-up & $\mathrm{P}=0.386$ & $\mathrm{P}=0.152$ & 0.482 \\
\hline Perceived control (baseline) & $5.9(5.6-6.2)$ & $6.0(5.9-6.2)$ & \\
\hline Perceived control (follow-up) & $6.2(5.9-6.6)$ & $6.2(6.0-6.3)$ & \\
\hline Baseline/follow-up & $\mathrm{P}=0.155$ & $\mathrm{P}=0.113$ & 0.516 \\
\hline Intention (baseline) & $4.1(3.8-4.4)$ & $4.4(4.3-4.6)$ & \\
\hline Intention (follow-up) & $4.4(4.3-4.7)$ & $4.5(4.4-4.6)$ & \\
\hline Baseline/ follow-up & $\mathrm{P}=0.090$ & $\mathrm{P}=0.337$ & 0.261 \\
\hline Sugared foods (baseline) & $8.6(8.0-9.3)$ & $9.0(8.6-9.2)$ & \\
\hline Sugared foods (follow-up) & $8.9(8.3-9.5)$ & $8.8(8.5-9.1)$ & \\
\hline Baseline/ follow-up & $\mathrm{P}=0.521$ & $\mathrm{P}=0.461$ & 0.364 \\
\hline Tooth brushing (baseline) & $3.1(2.9-3.1)$ & $3.0(2.9-3.1)$ & \\
\hline Tooth brushing (follow-up) & $3.2(3.1-3.2)$ & $3.2(3.2-3.2)$ & \\
\hline Baseline/ follow-up & $\mathrm{P}=0.092$ & $\mathrm{P}=0.001$ & 0.164 \\
\hline Knowledge (baseline) & $15.1(14.9-15.4)$ & $15.1(14.5-15.6)$ & \\
\hline Knowledge (follow-up) & $14.2(14.0-14.4)$ & $14.1(13.7-14.6)$ & \\
\hline Baseline/ follow-up & $\mathrm{P}=0.001$ & $\mathrm{P}=0.005$ & 0.850 \\
\hline
\end{tabular}

(mean scores 10.9 versus $10.7, \mathrm{p}<0.05$ ). No changes in the mean scores of intention, subjective norm, perceived behavioural control, and sugar consumption were observed in either group. Tooth brushing improvement was statistically significantly $(3.0$ versus $3.2, \mathrm{p}<0.001$ ) among students receiving OHE only. Oral health related knowledge improved among students receiving ART/OHE (15.1 versus 14.2, $\mathrm{p}<0.001)$ and among those having OHE only (15.1 versus $14.1, \mathrm{p}<0.001)$. As there were no statistically significant differences in change scores between the two intervention groups, all measures from the two groups were pooled and analysed further according to change scores of intended sugar avoidance and oral knowledge. GLM repeated measures revealed statistically significant two-way interactions between change groups of intention on the one hand side and attitudes, subjective norms, perceived behavioural control, and sugar consumption on the other hand side (Table 5). Following the TPB, changes in attitudes, subjective norms and perceived control with respect to sugar avoidance discriminated between those who improved, were stable and deteriorated intended sugar avoidance (Table 5). Attitudes, subjective norms and perceived control deteriorated and improved in subjects who respectively, deteriorated and improved their intention to avoid sugared snacks. Moreover, sugar consumption decreased statistically significantly in subjects who improved their intended sugar avoidance between baseline and follow up. As shown in Table 5, GLM repeated measures revealed 
Table 5. Mean scores and $95 \%$ CI for attitudes, subjective norms, perceived control and sugar behaviour by change in intended sugar avoidance (INT). GLM repeated measures.

\begin{tabular}{|c|c|c|c|c|}
\hline & $\begin{array}{l}\text { Deteriorated INT score } \\
(\mathrm{n}=553)^{\mathrm{a}}\end{array}$ & $\begin{array}{l}\text { Stable INT score } \\
\quad(\mathrm{n}=278)^{\mathrm{a}}\end{array}$ & $\begin{array}{c}\text { Improved INT score } \\
(\mathrm{n}=477)^{\mathrm{a}}\end{array}$ & Factor $\mathrm{x}$ group ${ }^{\mathrm{b}}$ \\
\hline & $\mathrm{M}(95 \% \mathrm{CI})$ & $\mathrm{M}(95 \% \mathrm{CI})$ & $\mathrm{M}(95 \% \mathrm{CI})$ & $\mathrm{P}$ value \\
\hline Attitude (Baseline) & $10.6(10.4-10.8)$ & $10.6(10.3-10.9)$ & $11.4(11.2-11.6)$ & \\
\hline Attitude (Follow-up) & $11.3(11.1-11.6)$ & $10.2(9.9-10.5)$ & $10.2(10.0-10.4)$ & \\
\hline Baseline/ follow-up & $\mathrm{P}=0.001$ & $\mathrm{P}=0.029$ & $\mathrm{P}=0.001$ & 0.001 \\
\hline Subjective norm (baseline) & $2.0(1.9-2.1)$ & $2.2(2.0-2.3)$ & $2.7(2.6-2.8)$ & \\
\hline Subjective norm (follow-up) & $2.7(2.6-2.8)$ & $2.2(2.1-2.4)$ & $2.0(1.9-2.1)$ & \\
\hline Baseline/ follow-up & $\mathrm{P}=0.001$ & $\mathrm{P}=0.596$ & $\mathrm{P}=0.001$ & 0.001 \\
\hline Perceived control (baseline) & $5.5(5.3-5.7)$ & $5.8(5.6-6.1)$ & $6.8(6.6-7.0)$ & \\
\hline Perceived control (follow-up) & $6.8(6.6-7.1)$ & $5.9(5.6-6.1)$ & $5.6(5.4-5.9)$ & \\
\hline Baseline/ follow-up & $\mathrm{P}=0.001$ & $\mathrm{P}=0.786$ & $\mathrm{P}=0.001$ & 0.001 \\
\hline Sugar (baseline) & $8.8(8.4-9.2)$ & $8.9(8.3-9.4)$ & $8.9(8.5-9.4)$ & \\
\hline Sugar (follow-up) & $9.1(8.7-9.5)$ & $9.1(8.6-9.6)$ & $8.3(7.9-8.7)$ & 0.01 \\
\hline \multirow[t]{2}{*}{ Baseline/ follow-up } & $\mathrm{P}=0.171$ & $\mathrm{P}=0.669$ & $\mathrm{P}=0.009$ & \\
\hline & $\begin{array}{l}\text { Deteriorated knowledge } \\
\text { score }(\mathrm{n}=485)\end{array}$ & $\begin{array}{l}\text { Neutral knowledge } \\
\text { score }(n=120)\end{array}$ & $\begin{array}{l}\text { Improved knowledge } \\
\text { score }(\mathrm{n}=703)\end{array}$ & \\
\hline Attitude (baseline) & $10.6(10.4-10.9)$ & $10.7(10.3-11.2)$ & $11.2(10.9-11.3)$ & \\
\hline Attitude (follow-up) & $10.9(10.3-11.2)$ & $10.6(10.1-11.0)$ & $10.6(10.4-10.8)$ & \\
\hline Baseline/ follow-up & $\mathrm{P}=0.071$ & $\mathrm{P}=0.567$ & $\mathrm{P}=0.001$ & 0.001 \\
\hline Tooth brushing (baseline) & $3.0(2.9-3.1)$ & $3.0(2.8-3.1)$ & $3.2(3.2-3.3)$ & \\
\hline Tooth brushing (follow-up) & $3.1(3.1-3.2)$ & $3.3(3.1-3.2)$ & $2.9(2.9-3.0)$ & \\
\hline Baseline/ follow-up & $\mathrm{P}=0.008$ & $\mathrm{P}=0.001$ & $\mathrm{P}=0.001$ & 0.054 \\
\hline Sugar (baseline) & $8.8(8.1-9.5)$ & $8.9(8.1-9.7)$ & $8.4(8.0-8.9)$ & \\
\hline Sugar (follow-up) & $8.6(7.9-9.2)$ & $8.5(7.6-9.2)$ & $8.8(8.4-9.3)$ & \\
\hline Baseline/ follow-up & $\mathrm{P}=0.907$ & $\mathrm{P}=0.671$ & $\mathrm{P}=0.384$ & 0.633 \\
\hline
\end{tabular}

${ }^{\text {a }}$ Paired t-test

${ }^{\mathrm{b}}$ GLM repeated measure controlled for age and gender

statistically significant two-way interactions between knowledge change groups on the one hand side and attitudes towards sugar avoidance. Attitudes towards sugar avoidance and students' tooth brushing increased in students who improved their oral knowledge and deteriorated in students who deteriorated their knowledge. Changes in sugar consumption were not related to changes in oral health related knowledge.

\section{DISCUSSION}

This study has shown that a combined intervention of ART and OHE implemented by oral health care staff and teachers in primary school, improved students' oral health related knowledge, attitudes towards sugar avoidance, and tooth brushing frequency, but had no effect on their motivation to avoid sugared snacks and their self-reported level of sugar consumption. Following the intervention, changes in TPB specific cognitions were related to changes in intended sugar avoidance and to changes in self-reported sugar intake as predicted by the TPB. Thus, interactive communication with students targeting cognitions by verbal instructions and being supported by reminders from teacher fostered behavioural change, in accordance with socio-cognitive models, such as the TPB (18). However, as shown in Table 3, the effect sizes amoun- ted at best to 0.3 (tooth brushing), thus reflecting small changes according to the benchmarks defined by Cohen (27). The weak effect observed might be explained, partly, by the short-time intervention of 6 months and partly by the fact that the Tanzanian primary school system suffers from extreme underfunding and bureaucratic inefficiency. Thus, the primary schools in rural areas face challenges that might undermine oral health interventions. Already at baseline, students reported low level of sugar consumption, performed tooth brushing with moderate frequency and reported strong intentions to avoid sugared snacks. The possibility that the change scores presented are confounded by regression to the mean effect, whereby those with more extreme scores at baseline tend to have less extreme scores at follow up, regardless of any real change in the characteristic being measured, cannot be overlooked. Moreover, simply growing up and becoming more mature might have contributed to some of the changes observed. Important learning might occur from administration of questionnaires alone prompting subjects to seek information about oral health. Kowash (28) showed a good cost-benefit ratio for OHE programs when compared to several other preventive approaches. In Tanzania, the relatively late age of school leavers and the low proportion of students who continue to secondary schools suggest that 
primary schools are currently the best institution to implement $\mathrm{OHE}$ at a relatively low cost and on a large scale. The self-report behavioural measures utilized in this study have been shown to correlate with oral hygiene measures and the frequency questionnaire on sugar consumption have been found to be acceptable to classify school children into broad categories of low and high sugar consumption (29).

A limitation of this study is not to have randomized subjects into intervention and control groups. Inclusion of a control group would have allowed for a valid comparison of changes in scores between groups (30). With some exceptions, few studies have employed a randomized controlled trial (RCT) design, making the evidence underpinning OHE programs relatively weak (31-32). Because the present study was designed to satisfy ethical requirements of the health authority and since available resources were limited, a true control group (i.e. delayed intervention group) could not be included. Nevertheless, the multiple groups before and after design enabled a simple assessment with respect to gain in knowledge and improvement in attitudes and behaviours following the minimal ART/OHE intervention. The study group examined at baseline was recognized to be fairly representative of the school-going adolescent population in the district of Kilwa. Despite a follow up rate of $73 \%$, non-response analyses showed differences in socio-demographic characteristics as well as in tooth brushing and attitudes, suggesting that follow-ups and non-responders had different background and were differently exposed to oral health information. On the other hand, the distribution of intervention groups remained stable throughout the follow-up period, indicating limited bias due to differential non-response.

Whereas improvement in tooth brushing and oral health knowledge was equally pronounced across intervention groups, students in the group without treatment need (OHE only) experienced the largest improvement in attitudes towards sugar avoidance. In accordance with the present results, interventions comprising elements of school based OHE have been found to be effective across behavioural domains (33). Strong reviews have shown that theory based educational programs produce better effects than nontheoretical programs. Psychological models of behavioural change such as the TPB, has been effective in improving adherence to oral hygiene instructions (34). Consistent with the present results, improvements with respect to oral cleanliness, gingival health, and oral health knowledge following school based OHE have been reported in both developing and developed countries (32,35-36). Whether the improved oral health related knowledge, attitudes and behaviours observed in this study will improve students' oral health status remains questionable. Thus, reservation has been raised as to the effectiveness of OHE in caries prevention. Several studies have found clinical prevention and OHE approaches alone to be unsuccessful in achieving sustainable improvements (37).

In accordance with the propositions of the TPB (19), students who declined and increased intended sugar avoidance, respectively declined and increased their corresponding cognitions related to sugar avoidance. Moreover, students who decreased and increased their intended sugar avoidance, respectively, increased and decreased their actual sugar consumption. This adds support to the TPB as a model of changing behaviour (38). Whether guidelines derived from the TPB lead to behavioural change in the desired direction should be evaluated in future studies using RCT design.

In summary, it seems that primary school students in a deprived rural area of Tanzania improved their oral health knowledge, attitudes towards sugar avoidance and tooth brushing frequency when exposed to school-based OHE and ART. The observed increase in tooth brushing frequency points to the importance of availability of oral remedies as a key factor in behavioural change. Similar improvement in sugar consumption was not observed. Probably, the short lasting intervention program was not sufficient to obtain restricted sugar consumption, suggesting that behavioural change is a long term process that unfolds over time. Support to the TPB as a model of changing behaviour was provided by confirming the hypotheses; that increased intention to avoid sugar products following intervention associated with changes towards more positive attitudes and reduced sugar consumption and that increased oral health related knowledge associated with more positive attitudes towards sugar avoidance.

\section{ACKNOWLEDGEMENTS}

This study was financially supported by the Faculty of Medicine and Dentistry and the Centre for International Health, University of Bergen and by Statens Lånekasse, Norway. The authors would like to acknowledge Kilwa district's administrative authorities, National Institute for Medical Research and Ministry of Health and Social Welfare in Tanzania. REK VEST of Norway is acknowledged for giving permission to conduct this study. Thanks to Jacqueline Joseph and Frank Mmbaga for their tireless work in the field and thanks to all participants.

\section{REFERENCES}

1. Rugarabamu PGN, Poulsen S, Masalu JRP. A longitudinal study of occlusal caries among schoolchildren in Dar es Salaam, Tanzania. Community Dent Oral Epidemiol 2002; 30: 47-51.

2. Scheutz F, Matee MI, Poulsen S, Frydenberg M. Caries risk factors in the permanent dentition of Tanzanian children: a cohort study (1997-2003). Community Dent Oral Epidemiol 2007; 35: 500-6. 
3. Mumghamba EG, Markkanen HA, Honkala E. Periodontal status and treatment needs in a rural area of Ukonga, Tanzania. In Dent J 1996; 46: 156-60.

4. Mashoto KO, Åstrøm AN, David J, Masalu JR. Dental pain, oral impacts and perceived need for dental treatment in Tanzanian schoolstudents: a cross-sectional study. Health Qual Life Outcomes 2009; 7:73.

5. Kerosuo E, Kerosio H, Kallio P, Nyandindi U. Oral health status among teenage schoolchildren in Dar es Salaam, Tanzania. Community Dent Oral Epidemiol 1986; 14: 338-40.

6. Kikwilu EN, Mandari GJ. Dental caries and periodontal conditions among primary school children in Morogoro municipality, Tanzania. East Afr Med J 2001; 78: 152-6.

7. MoHSW. Annual regional dental services reports. United Republic of Tanzania, Dar Es Salaam, Central Oral Health Unit, Ministry of Health and Social Welfare 2005; 11-3.

8. Nash DA. Friedman JF, et al. Dental therapists: a global perspective. Int Dent J 2008; 58: 61-70.

9. WHO. Atraumatic Restorative Treatment (ART) for Tooth Decay. Geneva, 1998.

10. Kikwilu EN, Frencken J, Mulder J. Impact of atraumatic restorative treatment (ART) on the treatment profile in pilot government dental clinic in Tanzania. BMC Oral Health 2009; 9: 14.

11. Petersen PE. Global policy for improvement of oral health in the 21 st century - implications to oral health research of World Health Assembly 2007, World Health Organization. Community Dent Oral Epidemiol 2009; 37: 1-8.

12. Nyandindi U, Palin-Palokas T, Millen A, et al. Oral health knowledge, attitudes, behaviour and skills of children entering school in urban and rural areas of Tanzania. Public Health 1994; 108: 35-40.

13. Ministry of Health. The National Plan for oral health for 1988-2000. The United Republic of Tanzania, 1994; 6-7.

14. Mtaya M. Self-reported oral health behaviors, knowledge, beliefs and sources of oral health information among students attending higher learning institutions in Tanzania. Thesis: ISBN 82-7815-039-7. Bergen: University of Bergen, Norway, 2000.

15. Masalu JR, Åstrøm AN. Predicting intended and self perceived sugar restriction among Tanzanian students using the theory of planned behaviour. J Health Psychol 2001; 6: 435-45.

16. Michie S, Abraham C, Whittington C, McAteer J. Effective techniques in healthy eating and physical activity interventions: a meta regression. Health Psychol 2009; 28: 690-701.

17 Ajzen I, Fishbein M. Understanding attitudes and predicting social behavior. Englewood Cliffs, NJ: Prentice Hall, 1980.

18. Ajzen I, Madden TJ. Prediction of goal directed behavior: Attitudes, intentions and perceived behavioral control. J Exp Soc Psychol 1986; 22: 453-74.

19. Armitage CJ, Conner M. Efficacy of the theory of planned behavior: a meta analytical review. Brit $J$ Soc Psychol 2002; 40: 471-99.

20. Sniehotta Ff, Soares VA, Combrowski SU. Randomized controlled trial of a one minute intervention changing oral self care behavior. $J$ Dent Res 2007; 86: 641-45.

21. Åstrøm AN, Okullo I. Temporal stability of the theory of planned behavior: a prospective analysis of sugar consumption among Ugandan adolescents. Community Dent Oral Epidemiol 2004; 32: 426-34.

22. Fife-Shaw C, Abrahams C. How much behavioral change should we expect from health promotion campaign targeting cognitions? An approach to pre-intervention assessment. Psychology and Health 2009; 24: 763-6.

23. http://www.tanzania.go.tz/census/lindi.html. Population and Housing Census 2002 retrieved 2009-26-10.

24. Mashoto KO, Åstrøm AN, Skeie MS , Masalu JR. Changes in the quality of life of Tanzanian schoolchildren after treatment interventions using the Child-OIDP. Eur J Oral Sci 2010; 118: 626-34.

25. Frencken JE, Songpaisan Y, Phantumvanit P, Pilot T. An Atraumatic Restorative Treatment (ART) technique: evaluation after one year. Int Dent J 1994; 44: 460-4.

26. Frencken JE, Phantumvanit P, Pilot T. Atraumatic Restorative Treatment technique of dental caries, 2nd ed. Groningen, the Netherlands: WHO Collaborating Centre for Oral Health Services Research, University of Groningen, 1994.

27. Cohen J. Statistical power analysis for the behavioral sciences. New York: Academic Press, 1977.

28. Kowash MB, Toumba KJ, Curzon ME. Cost-effectiveness of a long term dental health education program for the prevention of early childhood caries. Eur Arch Paediatr Dent 2006; 7: 130-5.

29. Kiwanuka SN, Åstrøm AN, Trovik TA. Sugar snack consumption in Ugandan schoolchildren: validity and reliability of a food frequency questionnaire. Community Dent Oral Epidemiol 2006; 34: 372-80.

30. Sibbald B, Roland M. Why are randomized controlled trials important? Br Med J 1998; 316: 201.

31. Redmond C, Blinkhorn FA, Kay E, Davies RM, Worthington HV, Blinkhorn A. A cluster randomized controlled trial testing the effectiveness of a school based dental health education program for adolescents. $J$ Public Health Dent 1999; 59: 12-7.

32. Saied-Moallemi Z, Virtanen JI, Vehkalathi MM, Tehranchi A, Murtomaa H. School-based intervention to promote preadolescent' gingival health: a community trial. Community Dent Oral Epidemiol 2009; 37: 518-26. 
33. Peters LWH, Kok G, Ten Dam G, Buijs G, Paulussen GWM. Effective elements of school health promotion across behavioral domains: a systematic review of reviews. BMC Public Health 2009; 9: 182.

34. Renz A, Ide M, Newton T, Robinson PG, Smith D. Psychological interventions to improve adherence to oral hygiene instructions in adults with periodontal diseases. Cochrane Database Syst Rev 2007; 2: CD005097.

35. Tolvanen M, Lahti S, Poulsen R, Seppa L, Pohjola V, Hausen H. Changes in children's oral health related behaviour, knowledge and attitudes during a $3.4 \mathrm{yr}$ randomized clinical trial and oral health promotion program. Eur J Oral Sci 2009; 117: 390-7.

36. Yevlahova D, Satur J. Models for individual oral health promotion and their effectiveness: a systematic review. Aust Dent J 2009; 54: 190-7.

37. Kay E, Locker D. A systematic review of the effectiveness of health promotion aimed at improving oral health. Community Dent Health 1998; 15: 132-44.

38. Hardeman W, Johnston M, Johnston DW, Bonetti D, Wareham NJ, Kinmonth AL. Application of the theory of planned behavior in behaviour change interventions: a systematic review. Psychology and Health 2002; 17: 123-58. 